\title{
РАСЧЕТ СОДЕРЖАНИЯ ЭКСТРАГИРУЕМЫХ СОЕДИНЕНИИ В ЖИДКИХ ОБЪЕКТАХ ПО ДАННЫМ МНОГОСТУПЕНЧАТОЙ ПЕРЕКРЕСТНОЙ ЭКСТРАКЦИИ
}

\author{
(Представил О. Эйзен)
}

В практике анализа технических жидких продуктов (напр., нефти и нефтепродуктов, смол термической переработки твердых горючих ископаемых, промышленных сточных вод и др.) нередко приходится сталкиваться с положением, когда прямое определение какого-либо соединения (или группы соединений) невозможно. Один из путей анализа таких смесей - предварительное выделение определяемого соединения из анализируемого продукта физико-химическим или химическим методами с дальнейшим анализом полученного концентрата. В числе методов выделения компонентов из сложной технической смеси особое место занимает экстракция водой или органическими экстрагентами. Естественно, что выбор экстрагента зависит от свойств анализируемого продукта. Но, как правило, ни один из экстрагентов при однократной обработке не обеспечивает полного извлечения данной группы соединений и в то же время любой экстрагент извлекает бо́льшую или меньшую часть соединений, относящихся к другим классам. Вследствие этого экстракцию нередко приходится проводить несколько раз, а общую концентрацию определяемого компонента рассчитывать путем суммирования и экстраполяции (до бесконечного числа обработок) полученных данных.

В ['] предложен метод определения водорастворимых соединений в смолах термической переработки твердых топлив. Метод включает в себя следующие операции: 1) многократную последовательную обработку изучаемой смолы (при постоянной температуре) определенным количеством воды в условиях, обеспечивающих практически полное равновесие между двумя жидкими фазами; 2) количественное определение водорастворимых соединений в полученных водных экстрактах; 3) расчет общего содержания водорастворимых соединений в смоле путем математической экстраполяции данных до бесконечного числа ступеней обработки. При этом исходят из предположения, что при низких концентрациях распределяющегося соединения и практически одинаковом составе органической фазы коэффициент межфазового распределения можно считать постоянной величиной.

При таком подходе достоверность получеиных результатов во многом зависит от метода экстраполяции, который, в принципе, не лишен определенных элементов субъективности. В основном они сводятся к трудностям при выборе критерия для оценки постоянства коэффициента распределения в конкретных случаях. Кроме того в расчетах используются экспериментальные данные только нескольких последних 
ступеней обработки, где анализ экстрактов связан с наибольшими относительными ошибками. Цель настоящей работы - разработка усовершенствованного, свободного от указанных недостатков метода, позволяющего рассчитать содержание экстрагируемых соединений по данным многоступенчатой экстракции.

Алгоритм расчета. Допустим, что для определения некоторого соединения проба анализируемого продукта экстрагируется последовательно $n$ порциями свежего экстрагента. В каждой ступени достигается равновесие фаз. Если при этом изотерма экстракции определяемого соединения описывается известным уравнением Нернста-Шилова, то во всех ступенях соблюдается равновесие:

$$
\frac{\left(c_{1}^{\prime}\right)^{r}}{c_{1}}=\frac{\left(c_{2}^{\prime}\right)^{r}}{c_{2}}=\ldots=\frac{\left(c_{i}^{\prime}\right)^{r}}{c_{i}}=\ldots=\frac{\left(c_{n-1}^{\prime}\right)^{r}}{c_{n-1}}=\frac{\left(c_{n}^{\prime}\right)^{r}}{c_{n}} \equiv \mathrm{K}
$$

где $c_{n}^{\prime}$ и $c$ - концентрации распределяющегося компонента в фазе рафината (анализируемого продукта) и экстракта соответственно; $K$ и $r$ - эмпирические константы; индексы $1,2, \ldots, i, \ldots ; n-1, n$ обозначают номера ступеней.

Обозначим объемы рафината и экстракта, полученные в каждой ступени, соответственно, через $Q^{\prime}$ и $Q$. Тогда концентрацию определяемого компонента в рафинате после любой $i$-й ступени можно выразить в виде:

$$
c_{i}^{\prime}=\sum_{j=i+1}^{\infty} c_{j} \frac{Q_{j}}{Q_{j}^{\prime}}=\sum_{j=i+1}^{n} c_{j} \frac{Q_{j}}{Q_{j}^{\prime}}+c_{n}^{\prime}
$$

где $c_{n}^{\prime}$ - концентрация определяемого компонента в рафинате после $n$-й ступени обработки; $j$ - номера ступеней, следующих за $i$-й $(j>i)$.

Тогда уравнение (1) для $i$-й ступени имеет вид:

$$
\frac{\left(\sum_{j=i+1}^{\infty} c_{j} \frac{Q_{j}}{Q_{j}^{\prime}}\right)^{r}}{c_{i}}=\frac{\left(\sum_{j=i+1}^{n} c_{j} \frac{Q_{j}}{Q_{j}^{\prime}}+c_{n}^{\prime}\right)^{r}}{c_{i}}=K
$$

или

$$
\lg c_{i}=r \lg \left(\sum_{j=i+1}^{n} c_{j} \frac{Q_{j}}{Q_{j}^{\prime}}+c_{n}^{\prime}\right)-\lg K
$$

Таким образом, на основании экспериментальных данных о концентрациях определяемого компонента в полученных экстрактах $\left(c_{1}, c_{2}, \ldots, c_{n-1}, c_{n}\right)$ можно составить систему из $n-1$ условных уравнений вида (4). Система условных уравнений решается на ЭВМ относительно неизвестных $r, c_{n}^{\prime}$ и $\lg K$ исходя из условия минимума остаточной дисперсии функции $c_{i}=f\left(c_{i}^{\prime}\right)$. .

Для решения системы уравнений (4) по специальной программе * в некотором интервале варьировали величиной $c_{n}^{\prime}$ с определенным шагом. Для каждого значения $c_{n}^{\prime}$ методом наименьших квадратов рассчитывали $r$ и $K$, а также остаточную дисперсию функции $c_{i}$ от пере-

* Программа написана на языке ФОРТРАН и реализована на ЭВМ ЕС 1022. 
Результаты расчета концентрации водорастворимых соединений во фракциях сланцевой смолы

\begin{tabular}{|c|c|c|c|c|}
\hline \multirow{2}{*}{$\begin{array}{l}\text { Анализируемая } \\
\text { фракция смолы }\end{array}$} & \multirow{2}{*}{$\begin{array}{l}\text { Определяемое } \\
\text { соединение }\end{array}$} & \multicolumn{2}{|c|}{$c_{0}^{\prime}, \%$} & \multirow{2}{*}{$\begin{array}{c}\Delta, \\
\text { отн. } \% *\end{array}$} \\
\hline & & метод 1 & метод 2 & \\
\hline $\begin{array}{l}\text { Фракция генера } \\
\text { торной смолы } \\
230-320^{\circ} \mathrm{C}\end{array}$ & $\begin{array}{l}\text { 5-метилрезорцин } \\
\text { 2,5-диметилрезорцин } \\
\text { 5-этилрезорцин } \\
4,5 \text {-диметилрезорцин } \\
8 \text { главных компонентов }\end{array}$ & $\begin{array}{l}0,350 \\
0,270 \\
0,468 \\
0,320 \\
2,379\end{array}$ & $\begin{array}{l}0,348 \\
0,272 \\
0,460 \\
0,296 \\
1,887\end{array}$ & $\begin{array}{r}+0,6 \\
-0,7 \\
+1,7 \\
+7,5 \\
+17,3\end{array}$ \\
\hline $\begin{array}{l}\text { Фракция дистил- } \\
\text { лята коксования } \\
\text { генераторной } \\
\text { смолы } 230- \\
320^{\circ} \mathrm{C}\end{array}$ & $\begin{array}{l}\text { 5-метилрезорцин } \\
\text { 2,5-диметилрезорцин } \\
\text { 5-этилрезорцин } \\
\text { 4,5-диметилрезорцин } \\
8 \text { главных компонентов }\end{array}$ & $\begin{array}{l}2,300 \\
1,120 \\
1,237 \\
0,959 \\
7,42\end{array}$ & $\begin{array}{l}2,300 \\
1,150 \\
1,255 \\
0,972 \\
7,33\end{array}$ & $\begin{array}{r}0,0 \\
-2,7 \\
-1,5 \\
-1,4 \\
+0,9\end{array}$ \\
\hline $\begin{array}{l}\text { Среднее } 10 \text { анали- } \\
\text { зов }\end{array}$ & & & & $3,4^{* *}$ \\
\hline$\underset{\text { Сов }}{\text { Средне }} 70$ анали. & & & & $4,9 * *$ \\
\hline
\end{tabular}

менной $c_{i}^{\prime} \equiv \sum_{j=i+1}^{n} c_{j} \frac{Q_{j}}{Q_{j}^{\prime}}+c_{n}^{\prime}$. Из полученного набора значений рассчитанных данных выбираем значения $r, K$ и $c_{n}^{\prime}$, соответствующие минимальной остаточной дисперсии. В нашей программе $c_{n}^{\prime}$ изменялось в интервале:

$$
-0,9 c_{n} \frac{Q_{n}}{Q_{n}^{\prime}} \leqslant c_{n}^{\prime} \leqslant 10 c_{n} \frac{Q_{n}}{Q_{n}^{\prime}},
$$

хотя в принципе $c_{n}^{\prime}$ может задаваться с любым шагом и в любом интервале.

Если известна $c_{n}^{\prime}$, то легко рассчитать исходную концентрацию определяемого соединения в анализируемой смеси $c_{0}^{\prime}$ :

$$
c_{0}^{\prime}=\sum_{j=1}^{n} c_{j} \frac{Q_{j}}{Q_{j}^{\prime}}+c_{n}^{\prime} \ldots
$$

Проверка алгоритма. Изложенный метод расчета был проверен на примере определения водорастворимых фенолов (алкилрезорцинов) в дистиллятных фракциях смолы термической переработки сланца-кукерсита. Для этого из дистиллятных фракций путем многократной перекрестной экстракции водой извлекали бо́льшую часть водорастворимых соединений. Экстракцию проводили путем интенсивного перемешивания (встряхивания) равных количеств смоляной фракции и воды в термостатированной делительной воронке в течение 30 мин и последующим тщательным расслаиванием (не менее 2 и). После разделения фаз рафинат (смоляная фаза) обрабатывался новой порцией воды, а экстракт (водная фаза) подвергался анализу аналогично [']. Опре- 
деляли содержание суммарных водорастворимых фенолов (методом конденсации формальдегидом) и их восьми главных компонентов (резорцин, 2-метилрезорцин, 5-метилрезорцин, 4,5-диметилрезорцин, 5-этилрезорцин, 2-метил-5-этилрезорцин и 2,4,5-триметилрезорцин), которые составляют $65-85 \%$ суммарных водорастворимых соедннений в данной фракции.

На основании полученных экспериментальных данных рассчитали исходные концентрации определяемых соединений в анализируемых фракциях $\left(c_{0}^{\prime}\right)$. Расчеты проводили на ЭВМ: (1) по изложенной в настоящей работе методике; (2) по методике, предложенной ранее в [1]. В качестве примера в таблице приводятся некоторые результаты.

Сопоставление полученных данных (всего 70 анализов) показало, что для индивидуальных соединений оба метода дают практически одинаковые результаты, но при первом методе экспериментальные точки несколько лучше удовлетворяют рассчитанным изотермам экстракции. Для суммарных водорастворимых фенолов, а также для суммы их главных 8 компонентов наблюдаются несколько бо́льшие расхождения в значениях $c_{0}^{\prime}$, полученных обоими методами, но они все же остаются на уровне погрешности самого анализа (среднее для 70 определений $4,9 \%$ ). В этом случае, несомненно, следует отдать предпочтение усовершенствованному методу экстраполяции, свободному от каких-либо элементов субъективности.

\section{Л И Т Е Р А У Р А}

1. Мэлдер. Л. И., Пурре Т. А., Арро Я. В., Халлик Э. К. Определение содержания водорастворимых соединений в смолах термической переработки твердых топлив, - Хим. тверд. топл., 1980, № 3, с. $73-77$.

Таллинский политехнический институт

Поступила в редакцию 3/IV 1981

\section{MOLDER, A. EBBER}

\section{MEETOD EKSTRAHEERITAVATE UHENDITE SISALDUSE ARVUTAMISEKS VEDELOBJEKTIDES PALJUASTMELISE RISTIVOOLUEKSTRAKTSIOONI ANDMETEST}

Meetodi rakendamiseks on vaja elektronarvutil lahendada võrrandsüsteem, mis seob ekstraheeruvate ühendite kontsentratsioonid tasakaalufaasides. Seejuures lähtutakse eeldusest, et iga ekstraheeruva ühendi jaotusisoterm on kirjeldatav Nernsti-Silovi võ:randiga. Meetodi kasutatavust on demonstreeritud andmetega vees lahustuvate alküülresortsiinide sisalduse kohta kukersiidiōli fraktsioonides.

\section{MOLDER, A. EBBER}

\section{CALCULATION OF THE EXTRACTABLE SOLUTE CONTENT IN LIQUID SAMPLES FROM MULTISTAGE CROSSCURRENT EXTRACTION DATA}

An improved method for calculating the content of extractable substances in liquid industrial samples from multistage crosscurrent contacting data has been developed. Calculation is based on the computer solution of series of equations connecting the concentrations of distributed substances in two coexistent equilibrium liquid phases. The application of the method is demonstrated via determining water soluble alkyl resorcinols in shale oil fractions. 